\title{
Epidemiological study of alcohol and tobacco consumption in people above 15 years of age in rural area of Nagpur, Maharashtra, India
}

\author{
Umesh Sinha*, Sumit Dutt Bhardwaj
}

Department of Community Medicine, Chirayu Medical College and Hospital, Bhainsakhedi, Bhopal, India

Received: 10 August 2016

Accepted: 06 September 2016

\section{*Correspondence:}

Dr. Umesh Sinha,

E-mail: umi_sinha@yahoo.com

Copyright: ( ) the author(s), publisher and licensee Medip Academy. This is an open-access article distributed under the terms of the Creative Commons Attribution Non-Commercial License, which permits unrestricted non-commercial use, distribution, and reproduction in any medium, provided the original work is properly cited.

\section{ABSTRACT}

Background: The World Health Organization predicts that tobacco deaths in India may exceed 1.5 million annually by 2020. Very few community-based studies have been conducted on the prevalence of alcohol use in India. Alcohol consumption has a U- shaped relation with ischemic heart disease and is as well a strong frisk factor for hepatic cirrhosis and many other type of injury.

Methods: It was a cross-sectional study, carried out in three villages of a PHC. A total of 3771 study subjects aged 15 years and above were included in the study. It was conducted from July 2007 to December 2009. General information and socio-economic details of study subjects were obtained. Details were recorded about personal habits like smoking, consumption of smokeless tobacco, alcohol. General and systemic examination was carried out and findings were recorded.

Results: In the present study, the prevalence of current smokers was $20.5 \%$ among males and none among females. In the present study the prevalence of smokeless tobacco use was $48.3 \%$ and the prevalence of current consumer of alcohol was $37.7 \%$ among males while there were none among the female.

Conclusions: we found a low prevalence of smoking tobacco and non-consumption of alcohol among females which can be attributed to the less social acceptability of smoking in this rural part of Nagpur, Maharashtra, India.

Keywords: Alcohol, Addiction, Tobacco, Smoking

\section{INTRODUCTION}

The World Health Organization predicts that tobacco deaths in India may exceed 1.5 million annually by 2020. ${ }^{1}$ Tobacco smoke contains 4000 harmful or poisonous chemical like nicotine, tar, carbon monoxide and many others. ${ }^{2}$ There is evidence that the earlier the person begins to smoke, the greater is the risk of life threatening diseases such as chronic bronchitis, emphysema, cardiovascular diseases and lung cancer. ${ }^{3}$

Very few community-based studies have been conducted on the prevalence of alcohol use in India. ${ }^{4-7}$ Alcohol consumption has a U- shaped relation with ischemic heart disease and is as well a strong frisk factor for hepatic cirrhosis and many other type of injury. People who drink light or moderate amounts have a lower death rate than non-drinkers while those who drink large amount have higher death rate. ${ }^{8}$ One standard drink or unit of alcohol contains about $10 \mathrm{gms}$ of alcohol. That is about one $250 \mathrm{ml}$ bottle of beer, one $100 \mathrm{ml}$ glass of wine, or one $25 \mathrm{ml}$ glass of whisky. ${ }^{9}$ The health hazards of smoking for the adults and young people are well established. The specific relation of cigarette- smoking to CHD has been documented in population studies.

Smoking interacts with other potent CHD precursor, so that even light smoking may carry a significant risk. Within low incidence population, with low level of other CHD risk factors, association has been found only after long follow up. ${ }^{10}$ Thus the present study was carried out to study the epidemiology of alcohol and tobacco consumption in people above 15 years of age in rural area of Nagpur. 


\section{METHODS}

The present cross-sectional community based study was carried out in three villages of PHC Khapa, namely Sawangi, Wakodi and Kodegaon, Tehsil Saoner, District Nagpur to study the prevalence of coronary heart disease and some known risk factors in people above 15 years in rural area of Nagpur. PHC Khapa was randomly selected to carry out the present study. In the present study, 5473 population was to be surveyed to meet our sample size of 3667 study subjects. Total population of Wakodi, Sawangi and Kodegaon was found to be 5624 in our study. 3980 population of these three villages was found to be aged 15 years and above which comprised the study universe. The present study was a part of a larger study whose sample size was calculated on the basis of prevalence of coronary heart disease through a pilot study on 405 study subject which was $4.58 \%$. Based on this prevalence, sample size was determined which came out to be 3667 . Duration of the study was from July 2007 to December 2009.

\section{Exclusion criteria}

Study subjects who were unavailable in spite of three informed home visits one week apart were excluded from the study. Thus out of 3980 study subjects aged 15 years and above, finally 3771 study subjects were included in the study.

\section{Methodology}

House to house survey was carried out in morning as well as evening hours to get maximum number of study subjects at home. Three visits were made to ensure maximum participation in the study. Those who were absent were asked to be present at the second visit. The interview technique was used as a tool for data collection. General information and socio-economic details of study subjects were obtained. Details were recorded about personal habits like smoking, consumption of smokeless tobacco, alcohol. General and systemic examination was carried out and findings were recorded.

\section{Statistical analysis}

Data was analyzed using percentage, $\mathrm{z}$ test, $\mathrm{x}^{2}$ test, and multiple logistic regression analysis with the help of STATA- 8 statistical software. ${ }^{10}$

\section{RESULTS}

The present study had seven age categories with a frequency interval of 10 years.

Table 1: Study subjects enrolled according to age and sex.

\begin{tabular}{|c|c|c|c|c|c|c|c|c|c|}
\hline \multirow{3}{*}{$\begin{array}{l}\text { Age group } \\
\text { in years }\end{array}$} & \multicolumn{9}{|c|}{ Study subjects } \\
\hline & \multicolumn{3}{|c|}{ Males } & \multicolumn{3}{|c|}{ Females } & \multicolumn{3}{|l|}{ Total } \\
\hline & Total & Enrolled & $\%$ & Total & Enrolled & $\%$ & Total & Enrolled & $\%$ \\
\hline $15-24$ & 627 & 586 & 93.5 & 561 & 526 & 93.8 & 1188 & 1112 & 93.6 \\
\hline $25-34$ & 474 & 450 & 94.9 & 485 & 471 & 96.9 & 959 & 921 & 96.0 \\
\hline $35-44$ & 392 & 377 & 96.2 & 327 & 318 & 98.1 & 719 & 695 & 96.7 \\
\hline $45-54$ & 249 & 233 & 93.6 & 187 & 179 & 94.2 & 436 & 412 & 94.5 \\
\hline $55-64$ & 194 & 185 & 95.4 & 196 & 181 & 94.8 & 390 & 366 & 93.8 \\
\hline $65-74$ & 126 & 115 & 91.3 & 120 & 115 & 96.6 & 246 & 230 & 93.5 \\
\hline$>=75$ & 24 & 18 & 75.0 & 18 & 17 & 94.4 & 42 & 35 & 83.3 \\
\hline TOTAL & 2086 & 1964 & 94.2 & 1894 & 1807 & 95.4 & 3980 & 3771 & 94.7 \\
\hline
\end{tabular}

Table 2: Mean duration (years) of smoking by the current smokers.

\begin{tabular}{|lll|}
\hline Age group in years & Current smokers & Mean duration (years) (SD) \\
\hline $15-24$ & $\mathbf{n}$ & $2.78 \pm 1.52$ \\
\hline $25-34$ & 29 & $9.90 \pm 4.05$ \\
\hline $35-44$ & 64 & $17.27 \pm 6.3$ \\
\hline $45-54$ & 94 & $26 \pm 7.09$ \\
\hline $55-64$ & 101 & $33.76 \pm 6.71$ \\
\hline $65-74$ & 65 & $40.69 \pm 7.10$ \\
\hline$\geq 75$ & 43 & $41.40 \pm 12.4$ \\
\hline Total & 07 & $22.57 \pm 13.17$ \\
\hline
\end{tabular}


It was observed that out of total enrolled 3771 study subjects, the maximum, $1112(29.5 .5 \%)$ study subjects belonged to the age group of 15-24 years followed by 921 $(24.4 \%)$ in the age group of 25-34 years. The mean age of the male and female study subjects was found to be $37.04 \pm 16.28$ years and $38.07 \pm 16.57$ years respectively (Table 1).

In the present study, the prevalence of current smokers was $20.5 \%$ among males and none among females. According to the present study the mean duration of smoking of 403 current smokers was $22.57 \pm 13.17$. The mean duration within the group give an estimate of initiation of smoking.

According to the present study, out of total 403 current smokers, maximum $143(35.5 \%)$ had frequency of smoking 11-15 times per day, followed by 16-20 times and 6-10 times per day in $93(23.1 \%)$ and $86(21.3 \%)$ respectively. The mean frequency of smoking per day was $14.92 \pm 7.4$.

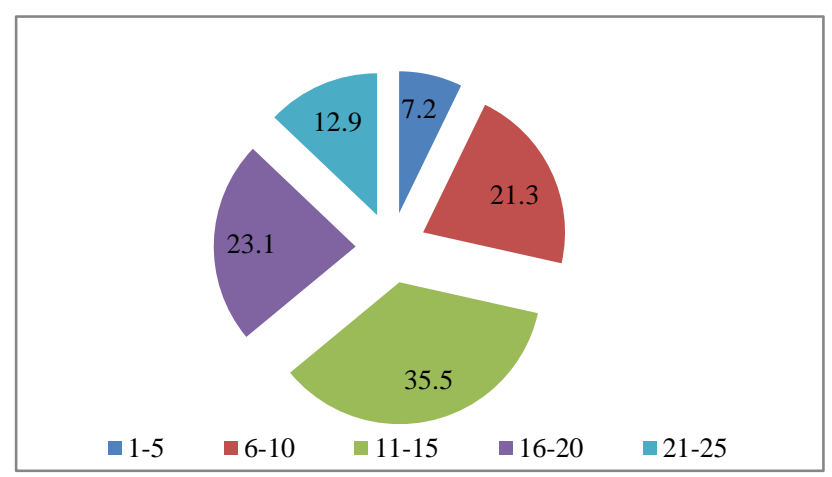

Figure 1: Distribution of current smokers by their frequency of smoking per day.

Table 3: Mean duration (years) of use of smokeless tobacco by current user of smokeless tobacco.

\begin{tabular}{|c|c|c|c|c|c|c|}
\hline \multirow{3}{*}{$\begin{array}{l}\text { Age } \\
\text { group } \\
\text { in } \\
\text { years }\end{array}$} & \multicolumn{6}{|c|}{ Current user of smokeless tobacco } \\
\hline & \multicolumn{2}{|c|}{ Males } & \multicolumn{2}{|c|}{ Females } & \multicolumn{2}{|c|}{ Total } \\
\hline & $\mathbf{n}$ & $\begin{array}{l}\text { Mean duration use } \\
\text { (years) (SD) }\end{array}$ & $\mathbf{n}$ & $\begin{array}{l}\text { Mean duration use } \\
\text { (years) (SD) }\end{array}$ & $\mathbf{n}$ & $\begin{array}{l}\text { Mean duration use } \\
\text { (years) (SD) }\end{array}$ \\
\hline $15-24$ & 256 & $5.37(3.0)$ & 48 & $5.29(2.29)$ & 304 & $5.36(2.90)$ \\
\hline $25-34$ & 342 & $10.72(4.9)$ & 144 & $8.9(4.8)$ & 486 & $10.21(4.9)$ \\
\hline $35-44$ & 293 & $16.63(6.3)$ & 138 & $13.01(7.2)$ & 431 & $15.48(6.81)$ \\
\hline $45-54$ & 137 & $25.93(7.51)$ & 79 & $18.86(8.14)$ & 216 & $23.34(8.45)$ \\
\hline $55-64$ & 126 & $26.76(7.44)$ & 110 & $18.90(11.16)$ & 236 & $24.17(8.77)$ \\
\hline $65-74$ & 66 & $32.68(11.63)$ & 66 & $25.83(8.85)$ & 132 & $29.25(10.85)$ \\
\hline$\geq 75$ & 10 & $39(20.4)$ & 7 & $28.57(11.80)$ & 17 & $34.70(17.63)$ \\
\hline Total & 1230 & $16.63(14.42)$ & 592 & $15.42(9.71)$ & 1822 & $16.06(13.38)$ \\
\hline
\end{tabular}

In the present study the prevalence of smokeless tobacco use was $48.3 \%$. According to the present study the mean duration of use of smokeless tobacco of all 1822 current user was $16.06 \pm 13.38$. In males it was $16.63 \pm 14.42$ while in females it was $15.42 \pm 9.71$. This difference was not found to be statistically significant. $(\mathrm{Z}=1.85, \mathrm{P}=0.065)$.

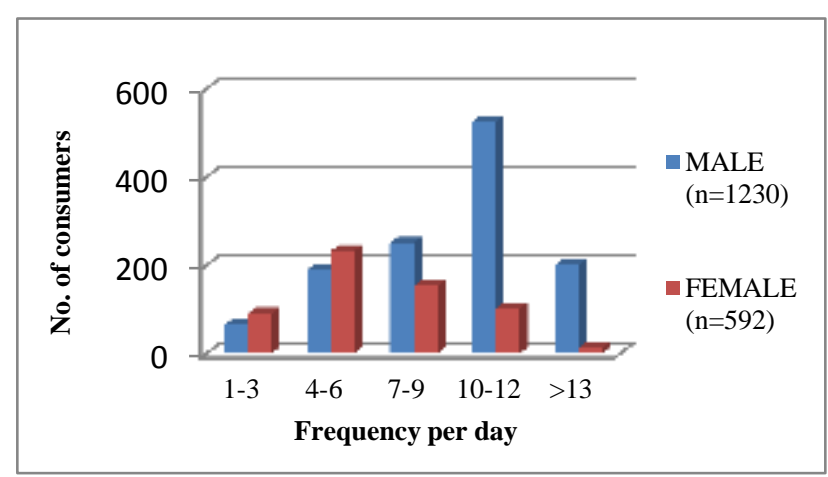

Figure 2: Distribution of current user by their frequency of smokeless tobacco consumption per day.
According to the present study, out of total 1822 current smokeless tobacco user, the maximum frequency of use was 10-12 times per day found in $628(34.5 \%)$ users, followed by 4-6 and 7-9 times per day in 422 (23.2\%) and $403(22.2 \%)$ users respectively.

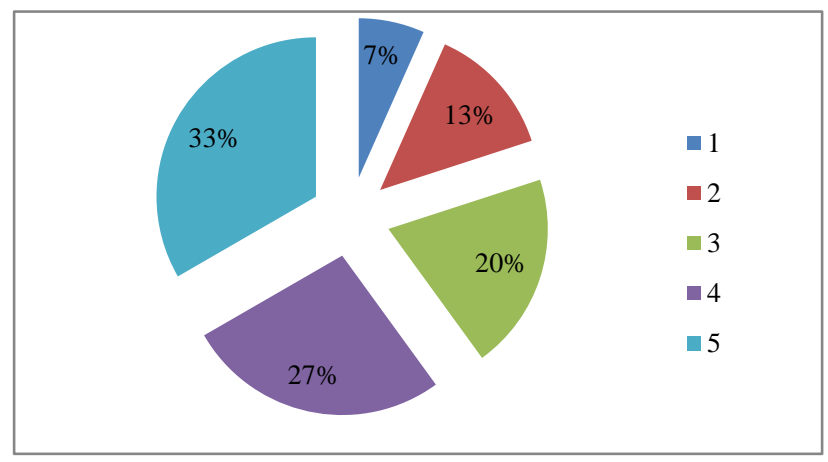

Figure 3: Distribution of current alcohol consumers by their number of standard drinks consumed per day. 
In males the maximum frequency $526(42.8 \%)$ was $10-12$ times per day of smokeless tobacco use while in females it was 4-6 times per day in $232(39.2 \%)$.

The mean frequency of use was $8.84 \pm 4.38$, in males was $9.8 \pm 4.49$ while in females it was $6.7 \pm 3.35$ times per day. This difference was found to be statistically significant. $(\mathrm{Z}=15.207, \mathrm{P}<0.001)$.

Table 4: Current consumer of alcohol with their mean duration (years) of consumption.

\begin{tabular}{|lll|}
\hline $\begin{array}{l}\text { Age group } \\
\text { in years }\end{array}$ & \multicolumn{2}{l|}{ Current consumer of Alcohol } \\
& No. & $\begin{array}{l}\text { Mean duration of } \\
\text { consumption (years) (SD) }\end{array}$ \\
\hline $15-24$ & 93 & $3.69(1.9)$ \\
\hline $25-34$ & 275 & $8.43(3.23)$ \\
\hline $35-44$ & 213 & $13.25(6.02)$ \\
\hline $45-54$ & 91 & $21.08(8.61)$ \\
\hline $55-64$ & 45 & $23.51(11.99)$ \\
\hline $65-74$ & 23 & $37.56(10.74)$ \\
\hline$\geq 75$ & 1 & $45($ na) \\
\hline Total & 741 & $12.60(9.31)$ \\
\hline
\end{tabular}

In the present study the prevalence of current consumer of alcohol was $37.7 \%$ among males while there were none among the female. According to the present study, the mean duration of consumption of total 741 current consumer of alcohol was $12.60 \pm 9.31$. The mean duration within the age group give approximate initiation of alcohol consumption by the study subject.

According to the present study, out of total 741 current consumer of alcohol, on the day when the study subject drank, maximum $341(46.0 \%)$ consumes 2 standard drinks. Only $12(1.7 \%)$ consumed 4 or more than 4 standard drinks. The mean number of standard drinks consumed was $1.89 \pm 1.01$.

\section{DISCUSSION}

In the present study, the prevalence of current smokers was $20.5 \%$ among males and none among females, similar findings were obtained from other studies. Anand $\mathrm{K}$ et al carried out a study on total 1263 male and 1326 female aged 15 years and above, selected using multistage systematic random sampling from urban area Haryana, found the prevalence current daily use of smoked tobacco was $22.2 \%$ (95\% CI; 20.0-24.6) for males and $1.4 \%$ (95\% CI: 0.9-2.2) for females. ${ }^{11}$

Mohan V et al carried out a study on 1175 study subjects from urban area of Chennai reported prevalence of current smokers was $13.5 \% .^{12}$

The reason for low prevalence of smoking tobacco among females can be attributed to the less social acceptability of smoking not only among women but also among men in this rural part of Nagpur. In the present study the mean duration of smoking among current smokers was $22.57 \pm 13.17$ years. Similar findings were obtained from other studies. ICMR-WHO multi-centric study on risk factors for Non Communicable diseases carried out a study on 44491 study subjects aged 15-64 years using WHO STEPS instrument from urban and rural areas of 5 different centers in India. The mean duration of smoking among the current smokers was $21.17 \pm 10$ years. $^{13}$

In the present study the mean frequency of smoking among the current smokers was $14.92 \pm 7.4$ times per day, the maximum of them smoked beedis which were easily and cheaply available in the rural area in comparison to cigarettes, similar results were reported from other studies. Similarly ICMR-WHO multi-centric study on risk factors for Non Communicable diseases reported the frequency of smoking was 14.55 times per day. ${ }^{14}$

In the present study the prevalence of smokeless tobacco use was $48.3 \%$ which was comparable with the other similar kind of studies, males had higher prevalence than females and it was statistically significant.

Mahanta TG et al carried out study on 510 study subjects aged 20-59 years from rural area of Assam, reported the prevalence of smokeless tobacco use are $78.4 \% .{ }^{14}$ In the present study the mean duration of use of smokeless tobacco was $16.06 \pm 13.38$ years, it was slightly higher in males than in females.

And the mean frequency of consumption per day was $8.84 \pm 4.38$; in males $(9.8 \pm 4.4)$ it was higher than females $(6.7 \pm 3.35)$ which was statistically significant. IEDCRWHO Behavioural risk factors of NCD in Bangladesh carried out a study on 11409 study subject aged 15 years and above from urban and rural area found the mean frequency of consumption were 6.95 times per day. The mean duration of consumption was $14.78 \pm 0.72$ years. ${ }^{15}$

In the present study the prevalence of current consumer of alcohol was $37.7 \%$ among males while there were none among the female. The finding of the study coincides with the finding of other studies. Krishan et al carried out a study on 2828 study subjects aged 15-64 years from rural area of Faridabad found the prevalence of alcohol intake $24.6 \%$ and $0 \%$ among males and females respectively. ${ }^{16}$

Dhupade NV et al carried out a study on 410 study subjects aged 19 years and above from rural area of Goa found the prevalence of alcohol consumption was $49 \% .^{17}$ Negi NS et al in a study on 490 males in rural area and 533 males from urban area aged 20 years and above from Dehradun found the prevalence of alcohol intake was $42.2 \%$ in rural area while in urban area it was $55.5 \%$. $^{18}$

The present study showed the mean duration of

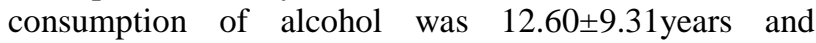
maximum current consumers of alcohol consume 2 
standard drinks on the day of consumption. The mean number of standard drinks was $1.89 \pm 1.01$.

There was only $1.7 \%$ who consumed more than 4 standard drinks. The reason for non-consumption of alcohol among females being drinking alcohol was not socially acceptable among females. These finding coincides and are comparable to the other similar type of study.

Khosla V et al carried out a study on 576 college students randomly selected from the 35 colleges of Ludhiana; found the prevalence of current alcohol consumption was $31.1 \%$ in males while in females it was none. On the day when the students drank, 42.6 per cent of them consumed three to four standard drinks on an average.

Close to one third of current drinkers $(32.7 \%)$ consumed 1-2 drinks and 24.8 per cent resorted to binge drinking (>5 standard drinks). ${ }^{19}$ SOLID-WHO multi-centric study on surveillance of risk factors for Non Communicable diseases in Nepal (2006) reported the mean number of standard drinks was $3.1 .^{20}$

\section{CONCLUSION}

In present study, we found a low prevalence of smoking tobacco and non-consumption of alcohol among females which can be attributed to the less social acceptability of smoking in this rural part of Nagpur.

The duration of consumption of smokeless tobacco in males and females was found to be almost same, as the younger females come in contact with smokeless tobacco mainly in the form of tobacco based toothpaste used in this part of rural Nagpur and young males mainly by eating gutkha, however the frequency of consumption per day among females remained low as eating tobacco even by the elder females in front of others was not socially acceptable in this part of rural area of Nagpur.

Funding: No funding sources

Conflict of interest: None declared

Ethical approval: The study was approved by the Institutional Ethics Committee

\section{REFERENCES}

1. Murray CJ, Lopez AD. The global burden of disease: a comprehensive assessment of mortality and disability from diseases, injuries and risk factors in 1990 and projected to 2020. Cambridge, Massachussets: Harvard School of Public Health, 1996.

2. Joshi P. IDSP NCD Risk factors surveillance training manual for field worker and supervisors. GOI-WHO. 2005.

3. World Health Organization. Hypertension Control: report of an expert committee. Technical Report Series No. 862. Geneva: WHO. 1996.
4. Ghosh S, Samanta A, Mukherjee S. Patterns of alcohol consumption among male adults at a slum in Kolkata, India. J Health Popul Nutr. 2012;30:73-81.

5. John A, Barman A, Bal D, Chandy G, Samuel J, Thokchom M, et al. Hazardous alcohol use in rural southern India: nature, prevalence and risk factors. Natl Med J India. 2009;22:123-5.

6. Gaunekar G, Patel V, Rane A. The impact and patterns of hazardous drinking amongst male industrial workers in Goa, India. Soc Psychiatry Psychiatr Epidemiol. 2005;40:267-75.

7. Krishnan A, Shah B, Lal V, Shukla DK, Paul E, Kapoor SK. Prevalence of risk factors for noncommunicable disease in a rural area of Faridabad district of Haryana. Indian $\mathbf{J}$ Public Health. 2008;52:117-9.

8. World Health Organization. Prevention of cardiovascular disease- Guidelines for assessment and management of cardiovascular risk. Geneva: WHO. 2007.

9. World Health Organization. Avoiding Heart Attacks, Geneva. WHO 2007.

10. World Health Organization. Technical Report Series No. 678. Geneva: WHO. 1982.

11. Anand K, Shah B, Gupta V, Khaparde K, Pau E, Menon GR, Kapoor SK. Risk factors for noncommunicable disease in urban Haryana: a study using the STEPS approach. Indian Heart J. 2008;60(1):9-18.

12. Mohan V, Deepa R, Premlatha G. Prevalence of coronary artery disease and its relationship to lipids in a selected population in south India: The Chennai Urban Population Study ( CUPS No.5). J Am Coll Cardiol. 2001;38(3):682-7.

13. Shah B, Mathur P. Multi-centric study on risk factors for Non Communicable diseases in India. Final Report. NCD-ICMR. 2005.

14. Mahanta TG, Ahmad FU, Mahanta BN, Barua A. Prevalence of hypertension and its risk factors in a tea garden community of Dibrugarh District, Assam. Indian J of Public Health. 2008;52(1):45-7.

15. IEDCR- WHO. Behavioural risk factors of NCD in Bangladesh. 2005.

16. Krishnan A, Shah B, Lal V, Shukla DK, Paul E, Kapoor SK. Prevalence of Risk factors for NonCommunicable disease in a rural area of Faridabad district of Haryana. Indian $\mathbf{J}$ Public Health. 2008;52(3): 117-25.

17. Dhupade NV, Motgahre DD, Prasad YD. Prevalence and pattern of alcohol consumption in rural Goa. Ind J Com Med. 2006;31(2):104-5.

18. Negi KS, Kandapal SD, Rawat CMS. Prevalence of alcoholisms among the males in a rural and urban area of district Dehradhun.(Uttarnchal). Indian J Prev and Soc Med. 2003;34(3):85-91.

19. Khosla V, Thankappan KR, Mini GK, Sarma PS. Prevalence \& predictors of alcohol use among college students in Ludhiana, Punjab, India. Indian J Med Res. 2008;128:79-81. 
20. SOLID- WHO. Multi - centric study on surveillance of risk factors for non-communicable disease in Nepal. 2006.
Cite this article as: Sinha U, Bhardwaj SD. Epidemiological study of alcohol and tobacco consumption in people above 15 years of age in rural area of Nagpur, Maharashtra, India. Int J Community Med Public Health 2016;3:2897-902. 